\title{
Of Parts and Politics: Onticology and Queer Politics
}

\section{Onticology and Queer Politics}

Objects are dynamic systems that exist at a variety of different scales of time and space, that are entangled in one another, that are operationally withdrawn from one another, that must reproduce themselves across time and space to sustain their existence, and that are defined by their affects, powers, or what they can do. ${ }^{1}$ Objects or substances are not a pole opposed to or standing in front of a subject. There is not one domain of being composed of objects and another domain of being composed of subjects. Rather, being is composed entirely of objects or systems. "Object" and "dynamic system" are synonyms. As a consequence, rocks, stars, tardigrades, aardvarks, corporations, nations, and subjects are equally objects. Some of these objects are parts of other objects. While objects can and do enter into relations with other objects, their being qua substances is characterized by "independent-being" or the ability to break with relations to other objects and enter into new relations with other systems.

In this regard, objects are not constituted by their relations, but rather all relations between objects are external to the objects related. The externality of relations is the condition under which change and emancipation is possible. All relations between objects are exo-relations. The fact that relations between objects are external does not entail that the severance of relations leaves the object severed unchanged. Clearly a frog severed from its relation to oxygen changes significantly. It dies. Yet "being-alive" is not the substantiality of the being of the frog, but rather a quality or local manifestation of the frog. The frog is still this frog, this substance, even though it is now dead. Proof of this lies in the fact that through certain medical interventions the frog can be resurrected. Likewise, a country cannot exist without its citizens, but these citizens sometimes renounce their citizenship, and, at any rate, live and die while the nation continues. Consequently, the substantiality of substances cannot be reduced to either their qualities or local manifestations, nor the parts out of which they are composed. Rather, the substantiality of a substance or system consists of its spatio-temporal endo-relations or its internal structure across time, coupled with the powers or affects of which the object is composed. This substantiality is the virtual proper being of an object, while the qualities an object actualizes or produces when it enters into relations with other objects are local manifestations of the object. 
Change the exo-relations in which the object exists and the local manifestations will often change as well. For example, a rock from Earth becomes lighter when placed on the moon and fire flows like water in outer space.

It is because objects exist at a variety of different scales and because they are entangled in one another that something like politics - or, following Isabelle Stengers and Bruno Latour, cosmopolitics - takes place and that all politics is essentially queer politics. Politics is what takes place when a part of an object rises up within another object and contests its status as a mere element of that object. As Rancière puts it,

...it is through the existence of this part of those who have no part, of this nothing that is all, that the community exists as a political community - that is, as divided by a fundamental dispute, by a dispute to do with the counting of the community's parts even more than of their "rights."

Politics is not the social, nor is it governance. Rather, politics is that moment where "the part of no part," that part that is not counted yet which nonetheless exists, appears and contests the mechanisms by which an assemblage counts and constitutes its elements.

It is for this reason that all genuine politics is queer politics. Politics is what takes place when something appears out of place or when that which should not appear appears within another object. The etymology of queer has it that the term appeared in the 1500 s, denoting that which is,

"strange, peculiar, eccentric," from Scottish, perhaps from Low Ger. (Brunswick dialect) queer "oblique, off-center," related to Ger. quer "oblique, perverse, odd," from O.H.G. twerh "oblique," from PIE base *twerk- "to turn, twist, wind" (related to thwart). The verb "to spoil, ruin" is first recorded 1812. Sense of "homosexual" first recorded 1922; the noun in this sense is 1935 , from the adj. ${ }^{3}$

Increasingly queer theory has experienced a crisis revolving around what, precisely, it is about and whether it has an subject. ${ }^{4}$ This state of affairs should not, however, be seen as a crisis but as marking the essentially mobile and empty place of the political as such. If politics finds that it lacks a single theme and object, then this is because politics is essentially evental, marking the contingency of any social order, such that what occurs at this site is the appearance of an object that is uncounted by a larger-scale object or system. The political is the appearance of the "odd," the in-apparent (from the standpoint of the larger scale object and its mechanisms of counting), of that which is out of place in a social system or larger scale object, and is that which turns and twists that larger scale object forcing re-organization and evolution. Politics always revolves around the appearance of that which does not appear. As such, politics marks the site of the volcanic anarchy that bubbles beneath any social organization, thereby announcing the contingency of that order. Queer should thus not be restricted to politics surrounding sexual orientations and gender - though we will see that there are essential reasons that queer theory first stumbled on these anarchic sites of twisting and oddness - but rather should be generalized to any process that is genuinely political whether it be the proletarian announcing itself, civil rights movements, suffrage movements, ecological movements, and so on. However, we require an account of just why politics is necessarily queer politics. Let us look a bit more closely at these issues of scale and entanglement to see why this is so. 
While many things are social, nothing, in and of itself, is political. Anything can become a site of politics, but not everything is political. ${ }^{5}$ Rather, politics is an event that occurs under very specific circumstances and the procedures that arise from this event as a result of a disrelation between larger and smaller-scale objects. It is only in this dis-relation, in this revelation of the absence of a relation where hitherto a relation was thought to exist, that politics takes place. As a consequence, politics is essentially rare. Much of what we often call politics is governance rather than politics. Governance consists of the manner in which a larger-scale object strives to maintain its structure or organization in its adventure across time and space by domesticating and regulating the elements of which it is composed. Governance consists of the mechanisms by which elements are counted and constituted within an assemblage of entities. Politics, by contrast, challenges the manner in which the larger-scale object counts or fails to count other objects, challenges the status of those objects that animate it as elements, instead announcing themselves as parts, and sets about either severing relations to this larger scale object, demolishing this relation, or reconfiguring it.

\section{Objects and Dynamic Systems}

The intelligibility of this thesis consists in understanding that the substantiality of objects does not consist in their materiality - though there are no objects that are not also material - but rather their status as dynamic systems. The class of objects is not restricted to chairs, stars, muskrats, computers, and things like burritos, but also consists of armies, workplaces, classrooms, movements, states, and a variety of other entities besides. If something like an army is an object, then this is because it has an endorelational structure defining relations between elements, such that the appearance of any particular element within it in a particular place or position has a low degree of probability. Unlike a crowd, the units that make up an army have distinct positions and identities with respect to one another (generals, majors, infantry, etc.), thereby indicating that the army has a low degree of entropy. As such, it constitutes a unity over and above its elements that constitutes their being as a substance or object. This unity, of course, must be maintained across time, fighting entropy and disintegration, and entities such as armies do this by perpetually producing and reproducing their elements and organization.

Objects are topologically malleable systems that are defined by their ongoing organization across time and space and their powers of acting, rather than any qualities they might currently manifest or materiality they might currently possess. In their article "Autopoiesis," Maturana and Varela distinguish between two types of systems or objects: allopoietic machines and autopoietic machines. ${ }^{6}$ Allopoietic machines, objects, or systems are produced by something other than themselves and are objects that weakly maintain their existence across time and space. An asteroid, for example, is largely the result of gravitational forces that attracted various particles of matter to one another. It does not strive to maintain its existence with the particular organization or configuration that it possesses, but rather only maintains its organization through its internal atomic forces. If hit with sufficient force it breaks apart and does not strive to reproduce it past organization. As such, allopoietic objects do not actively stave off increases in entropy within themselves. Finally, allopoietic objects cannot initiate their own action. Rocks 
do not produce their own local manifestations, but rather only produce the local manifestations they have as a result of being acted upon by other entities and intensities. For example, the qualities or local manifestations a rock possesses might result from the conditions of pressure and temperature under which it develops, generating this particular shape, this particular color, these particular crystalline patterns, and so on. These qualities or local manifestations are actualized in the rock by something other than the rock.

By contrast, autopoietic machines are,

...organized (defined as a unity) as a network of processes of production (transformation and destruction) of components that produce the components which: (i) through their interactions and transformations continuously regenerate and realize the network of processes (relations) that produce them; and (ii) constitute (the machine) as a concrete unity in the space in which they (the components) exist by specifying the topological domain of its realization as such a network. ${ }^{7}$

Where allopoietic machines are produced by something other than themselves, autopoietic machines produce themselves. Where allopoietic machines are indifferent to the continued maintenance and organization of their existence, autopoietic machines strive to maintain a particular organization. For example, if I am cut this wound does not simply persist but heals, and it heals in a way that reproduces the earlier organization of my body prior to being cut. Where allopoietic machines are constituted out of elements other than themselves (the particles out of which the asteroid is constructed, for example), autopoietic machines use matters other than themselves to constitute their own elements or components. As Niklas Luhmann, deeply influenced by Maturana and Varela, puts it, “...element[s] [are] constituted as a unity only by the [autopoietic] system that enlists it as an element to use in its relations." ${ }^{\prime 8}$ All objects are either allopoietic or autopoietic machines.

Where Maturana and Varela restrict autopoietic machines to the domain of living entities such as wombats, Luhmann, in Social Systems, extends the domain of autopoietic objects to social systems (we could also include entities such as tornadoes and hurricanes under the umbrella of autopoietic systems). Let us take the example of a classroom to illustrate this point. Classes are entities, substances, or systems in their own right. They are neither the sum of their parts nor the bodies of which they are composed (students, the professor), nor reducible to any of the events that take place within them. Rather, the class as a class consists of a network of relations in which the elements that compose the class (students, professor) are simultaneously constituted by the class and constitute the class. The students constitute the professor and other students as an element in this system through their actions towards the professor and other students, and the professor constitutes the students as students through his or her actions towards the students. The class as a whole has a regulative and constraining effect on the individual students and the professor, and also constitutes these elements. Luhmann remarks that "...the unity of element... is not ontically pre-given." The elements of an object are not intrinsic features of that part, but rather " $[\mathrm{t}]$ he elements acquire quality only insofar as they are viewed relationally, and thus refer to one another." 10 Thus there is no being that is intrinsically a professor or a student, there is no entity that is intrinsically an assignment or an 
answer to a question posed in class, but rather these elements are only constituted as elements as a consequence of belonging to the system of the class and of relating to one another in particular ways. Finally, it is through the constant interaction of these elements that these elements are constituted as the elements that they are. It is through these interactions that the class maintains itself as this class across time and space. It is in this way that the class is a substance and a dynamic system.

\section{Elements and Parts}

It is crucial not to confuse elements in a system with objects. Objects necessarily have independent or autonomous existence such that their relations to other entities can be severed. Yet elements only ever exist as elements for a system. Nonetheless, systems must be built out of something. As Luhmann observes, we "...must distinguish between the environment of a system and systems in the environment of this system."11 Insofar as allopoietic and autopoietic machines or systems are exhaustive of what exists, it follows that systems construct their elements out of other systems or autonomous objects. A professor and students might not exist independent of a class that constitutes them, but these elements are nonetheless constituted from other objects or systems; to wit, the persons or psycho-biological systems that come to occupy these roles.

Following Badiou's convention, I thus distinguish between the elements of a system and the parts of a system, or between membership and inclusion. ${ }^{12}$ An element or a member of a set exists only for the system in question, and is defined relationally such that its being consists only in its relations to other elements in the system. This is what I refer to as the "endo-consistency" of an object or system. Endo-consistency consists of the elements of a system or object, along with the way in which they are related to one another. The parts of a system, by contrast, are those other systems out of which a system constitutes its elements, are autonomous entities in their own right, and are always in excess of the elements that compose a larger-scale system. Mathematically there are always more possible relations among parts of a system than are admitted by the organization and elements in a system. As Hallward writes,

The elements of a national set can be distinguished [... according to the subsets of tax-payers or prison inmates, social security recipients or registered voters, and so on. The elements of these subsets all belong to the national set, and in their "substance" remain indifferent to the count effected by any particular subset. To belong to the subset of French taxpayers has nothing to do with the substantial complexity of any individual taxpayer as a living, thinking person. Such elemental complexity is always held to be infinitely multiple, nothing more or less. ${ }^{13}$

The point here is that the systems or parts in the environment of another system can always go uncounted, thereby being completely unregistered by the system of which they are parts, always have more complex qualities than are recognized by the system (the class is indifferent to what the student had for dinner), and can be related in other ways not sanctioned by the larger scale system. For example, prior to the 1967 Supreme Court decision Loving versus Virginia, African-Americans and whites were prohibited from marrying. Both African-Americans and whites were elements of the U.S. social system, yet this particular way of combining or relating elements was 
foreclosed by the social system. Put differently, an interracial couple could not be counted as an element in the U.S. social system, though at the level of parts such couplings could and did exist. Larger scale objects or systems thus strive to regulate and restrict the admissible relations that can occur between the elements that constitute them.

It is here that we encounter the volcanic anarchy that bubbles beneath any object or system. The parts of any system are always in excess of the elements recognized by any system in number, powers, qualities, and possible combinations. Not only are there always more parts than are counted as elements by a system - for example, in Hallward's example above prison inmates might not be counted as elements by the national system despite the fact that they are parts - but there are always more ways of relating parts to form distinct elements than are recognized by the system. It is here that politics emerges, in this strife or polemos between elements and parts. Politics occurs at that precise moment where parts appear qua part, refusing and contesting the manner in which they have been counted or not counted as elements, and refusing the regulation of admissible relations from the standpoint of the larger scale object or system. Politics is the appearance of that which is not counted as an element by the system, of that which, from the standpoint of the system, does not exist, and is for this reason the appearance of the queer or odd. As Rancière argues, "[p]olitics arises from a count of community 'parts,' which is always a false count, a double count, or a miscount." ${ }^{\prime 14}$ A double count within a system would consist in counting some elements as counting for more than other elements as in the case of oligarchies where the wealthy count more than workers and the poor, or in sexist social structures where men count more than women, in theocracies where believers count more than non-believers, or in racist societies where one group is counted more than others. In the case of politics borne of an unjust double count, certain elements are counted as elements belonging to the system or community, while nonetheless having less of a voice or say in those systems. By contrast, in the case of a miscount, certain parts are included in the system, but are not elements and members of the system. For example, illegal immigrants are parts of the U.S. social system but are not counted as elements of this system. They are included without belonging, and as such they exist without appearing. If the false count, the double count, and the miscount are the sole and only sites of the political, then this is because only the appearance of that which is uncounted and miscounted marks the anarchy beneath any organization, the contingency of any organization, that raises the question of how things ought to be organized altogether. Everything else is governance or the maintenance of elements. Only politics contests elements and their relations. Governance, by contrast, aims at the reproduction of elements and their relations. Governance and politics are thus antonyms.

\section{Withdrawal, Distinctions, and Operational Closure}

The rarity of politics arises from the way in which systems relate to their elements and environment. Every system both constitutes its own elements and their relation to one another and the unity of their environment. As Luhmann writes, “...the point of departure for all systems-theoretical analysis must be the difference between system and environment. Systems are oriented by their environment not just occasionally and adaptively, but structurally and they cannot exist without an 
environment. They constitute and maintain themselves by creating and maintaining a difference from their environment, and they use their boundaries to regulate this difference." 15 This distinction between system and environment arises from the fact that the environment of a system is always more complex than the system itself. As a consequence, systems cannot establish a one-to-one correspondence between themselves and their environment. This entails that systems must be selective and that therefore every system involves risk. As Luhmann remarks, "[c]omplexity [...] means being forced to select; being forced to select means contingency; and contingency means risk." ${ }^{16}$ Every system risks coming up against something in its environment that was not anticipated or that threatens to destroy it.

However, it would be a mistake to assume that the environment of a system is like a container within which the system exists. The distinction between system and environment is drawn by the system itself. In other words, the distinction between system and environment is selfreferential in that it is a distinction that the system itself draws. ${ }^{17}$ As a consequence, "[t]he environment receives its unity through the system and only in relation to the system." ${ }^{\prime 18}$ For the sake of clarity it would here be helpful to distinguish between world and earth. World is the environment that a system or object constitutes and to which an object is open under conditions of operational closure. Earth, by contrast, would be what would exist regardless of whether or not any system existed or drew a distinction between system and environment.

The consequence of this is that systems never directly relate to other objects or systems that populate the earth. As Luhmann writes elsewhere, the "[...] distinction between self-reference and other-reference cannot exist in the system's environment $[\ldots]$ but rather only within the system itself." ${ }^{19}$ In other words, the distinction between selfreference (reference to an event that transpires within the system) and other-reference (reference to events that occur outside the system) is 1) itself an event that takes place within the system, and 2) a distinction drawn by the system. For example, the distinction I draw between a dream and an event in waking life is itself something that takes place within me as a psycho-biological system. It is a distinction that $I$ draw rather than a distinction that exists independent of me in the environment. The consequence of this is that there is no information transferred between systems, but rather systems constitute their own information as a result of irritations issuing from the environment. "There is no information that moves from without to within the system. For even the difference and the horizon of possibilities on the basis of which the information can be seen as a selection (that is, information) does not exist in the external world, but is a construct - that is, internal to the system." ${ }^{20}$ What counts as information is something constructed by the system in question. It is not something that exists out there in the world. Thus, for example, when the maintenance person appears to change a light bulb in the classroom, this event does not consist of an event or information for that system consisting of the class. As such, the appearance of the maintenance person does not lead the class to select a new system state.

In constructing information and making other-references to events transpiring in the environment, the system must draw distinctions. The ability for something to count as information or to make an other-reference requires a prior distinction. In order to indicate anything at all, a system 
must first draw a distinction. Imagine a piece of paper covered by "x's." How do we indicate some x's rather than others? We must first draw a distinction. Perhaps, for example, we draw a circle in the middle of the paper. This circle is the distinction and contains an inside and an outside, a marked space and an unmarked space. We can now indicate those x's that fall within the circle, and those x's that are outside the circle. Distinction is the manner in which a system both opens itself to its environment and the manner in which it constitutes its elements. In the case of a sports team, for example, it is the jersey that defines whether or not Tom is a member of the team, whereas Tom as a part that is the son of Paul is irrelevant to his status as an element of the team and thereby falls in the unmarked space. The shirt here functions as a marker of the distinction that constitutes Tom as a component or element of the team. The distinction does not exist out there in the world, but rather is the mechanism by which the system constitutes other systems in the world as elements of itself.

The drawing of a distinction as a way of relating to the environment and constituting elements generates what Luhmann calls "blind spots." As Luhmann remarks, "[f] or every [system], the unity of the distinction [it] uses for the designation of the one (and not the other) side [of the distinction] serves as a blind spot..."21 The distinctions a system uses generates blind spots in two ways. First, what falls outside of the distinction becomes invisible to the system that draws the distinction. For example, in the case of the circle drawn on the piece of paper, the x's outside the circle fall into darkness such that only the x's in the circle are indicated. Second, as Luhmann will remark elsewhere, that systems cannot distinguish between " [...] the world as it is and the world as it is being observed
[...]"22 In other words, in using distinctions to make indications either within itself or in its environment, the distinction used becomes invisible to the system in question. This generates a sort of transcendental or optical illusion in which those properties that are effects of the system deploying the distinction come to be seen as properties of the entities distinguished themselves. For example, the system constituting the sports team sees "being-a-member" of the team as an intrinsic feature of the team members, rather than as resulting from how this system draws distinctions. As a consequence, the parts a system uses to constitute its elements get reduced to the markers by which the elements are counted and constituted as elements (e.g., "wearing-a-red-jersey"), such that other features of the parts are rendered invisible.

In light of the foregoing, it is now possible to see how parts of a system can be invisible from the standpoint of the system. Insofar as systems use distinctions to count and constitute elements, and insofar as these mechanisms of counting and constitution render features of parts not counted by the system invisible, parts can be included within a system without being members of a system. Tom as son of Paul is not counted by the sports team to which he belongs. Elements falling on the unmarked side of the distinction are uncounted within the system. This is the onticological version of what Graham Harman, in his object-oriented philosophy, refers to as "withdrawal." 23 Harman argues that objects are withdrawn from one another such that they never directly relate to or encounter one another. Within the framework of onticology, "withdrawal" signifies that objects only ever relate to one another through system-specific distinctions and therefore never encounter each other as such. Insofar as objects are operationally closed with respect to one another they 
are withdrawn from one another; and insofar as objects are withdrawn from one another it is possible for parts to be invisible from the standpoint of systems. For systems the indications rendered possible on the basis of the system's distinctions exhaust what constitutes reality.

\section{Aesthetics and Distributions of the Sensible}

It is clear that the mechanisms by which a system both counts and constitutes its elements and relates to its environment have a deep relation to the aesthetic. If this is the case, then this is because the manner in which elements become visible within a system or environment of a system are aesthetic in character. In Difference and Repetition Deleuze distinguishes between two senses of aesthetics: the being of the sensible and the theory of art. ${ }^{24}$ The "being of the sensible" here refers to the conditions under which a particular form of sensibility is possible. Here Deleuze hearkens back to Kant's understanding of the "transcendental aesthetic" in the Critique of Pure Reason. ${ }^{25}$ The transcendental aesthetic refers not to what we sense, but rather to that organization or structure that allows an entity to sense this or that. This organization is not itself something that is sensed, but is the condition under which it is possible to sense something. To understand this point, consider the bat which senses the world through sonar. When the bat senses the movement of a particular insect through a sound profile, this is what is sensed. By contrast, that organization of the bat's body that allows it to sense in this way is the "being of the sensible." Where Kant restricts his exploration of the being of the sensible to human forms of sensibility, Deleuze extends this domain to the exploration of any organism whatsoever. Thus there will be a different being of the sensible, a different way of being open to their environments, for cats and electric eels. Moreover, for Deleuze, the various beings of the sensible will not be universal and $a$ priori in the strong sense of being eternal and unchanging, but will be the result of a genesis. Bats had to evolve sonar as a way of being open to their environments. The fact that various beings of the sensible are the result of a genesis or evolution allows Deleuze to argue that aesthetics in the first sense of mere "sensibility" also converges on the second sense of aesthetics as the theory of art. Forms of openness to the environment are genuine creations analogous to art.

The being of the sensible is thus one half of affect. In the Ethics, Spinoza defines affect as "[...] the affections of the body by which the body's power of activity is increased or diminished, assisted or checked, together with the ideas of these affections. ${ }^{26}$ On the one hand, affect refers to the capacity to be affected or the manner in which a system or object is open to its environment. I, for example, cannot be affected in the same way a bat can be affected. This form of affect is the being of the sensible to which Deleuze refers. On the other hand, affect refers to the capacities of a system or object to act; its various powers of acting. Bats have the capacity to fly. I have the capacity to run. One of the key political questions is that of how it is possible for one system or object to affect another system or object under conditions in which the object it strives to affect is operationally closed or governed by distinctions that render it only selectively open to its environment.

The environment of a system refers not only to other systems outside the system, but also the parts a system draws on to constitute its elements. In constituting elements and 
relating to events in its environment, a system's relation to parts and environment is conditional on a "being of the sensible," a transcendental aesthetic, that opens it to these internal and external environments. Rancière, in his work, has hit upon a similar idea in his work with his concept of the "distribution of the sensible." As Rancière writes,

I call the distribution of the sensible the system of self-evident facts of sense perception that simultaneously discloses the existence of something in common and the delimitations that define the respective parts and positions within it. A distribution of the sensible therefore establishes at one and the same time something common that is shared and exclusive parts. This apportionment of parts and positions is based on a distribution of spaces, times, and forms of activity that determines the very manner in which something in common lends itself to participation and in what way various individuals have a part in this distribution. Aristotle states that a citizen is someone who has a part in the act of governing and being governed. However, another form of distribution precedes this act of partaking in government: the distribution that determines those who have a part in the community of citizens. ${ }^{27}$

The distribution of the sensible is that endo-relational structure or organization that define elements that belong to a system, how they are to be related to one another, and the sort of events possible within a system or object. The distribution of the sensible is thus not merely the endo-relational structure of the object, but also the mechanisms by which the object constitutes its elements and the events that occur within it. Marx, for example, in Capital, does not merely argue that commodities are the elements visible within a capitalist system, but explores the mechanisms by which objects are transformed into commodities and take on value.
The elements of a system and their relations are not pre-given, but must be constituted as elements from one moment to the next. Every autopoietic system faces the question of how to sustain its existence from moment to moment, of how to combat entropy, and must thus engage in all sorts of operations to reproduce itself across time. Returning to the example of Marx, if exchange, wage labor, and the reinvestment of capital ceases then commodities cease to exist and value disappears. Commodity labor and exchange are system operations, processes, by which commodities and values are constituted.$^{28}$ Likewise, in the classroom, all sorts of operations or processes must occur to constitute the professor as a professor and the students as students. These operations will include the way in which the professor addresses the students, the giving of assignments, the posing of questions, grading, the way in which students relate to the professor, the questions they ask her, providing assignments to be graded, and so on. These operations are not merely actions on the part of the students and the professor, but are mechanisms, performances, operations, by which the elements of the classroom are constituted and by which they come to relate in a particular way. When events occur in the classroom that deviate from these operations in some way or another, negative feedback sets in, steering the elements that compose this assemblage to returns to their proper relations. The professor that spends too much time talking about her weekend, for example, is politely asked by a student whether they will discuss such and such an aspect of the material today. Here the professor had shifted from her assigned role in the class, flattened relations by treating the students as peers, such that the students step in to channel her back in the direction of her proper role. 
Objects must often enlist the agency of other objects in order to maintain themselves as the type of object they are. Here we can distinguish between dark objects, dim objects, bright objects, and rogue objects. A dark object is an object completely invisible to another system by virtue of falling in the blind spot of that other object's distinctions. From the standpoint of capitalism, for example, proletariat as the revolutionary class is a dark object. Dark objects are the parts of a system that do not themselves appear as elements in a system. Dim objects are objects that only dimly appear in a particular system. Dim objects appear in larger scale assemblages but are counted as only playing a marginal role in those systems. Bright objects are those objects counted as elements in a system. And finally, rogue objects are objects that circulate in and out of a variety of different systems or objects, perturbing them in a variety of ways, without being tied to any particular system.

Many objects must enlist rogue objects in order to reproduce themselves across time. This is seen, in particular, in the role that many technologies play in the constitution and reproduction of elements and their relations. Many technologies are not themselves counted as elements of the various social systems that populate the contemporary world, but are nonetheless conditions necessary for the maintenance and reproduction of these systems. Fiber optic cables, the internet, satellites, personal computers, televisions, etc., are all necessary conditions for relating human bodies distant from one another in time and space. If negentropic collectives are to be formed out of these human bodies as parts, technologies such as this are required to relate these bodies to one another. Absent this, the requisite organization required to form a unified system or operationally closed object cannot emerge to form the sort of unity required in order for something to count as a substance. Likewise, in the absence of automobiles, roads, and highways, the distribution of bodies between the suburbs and the city characteristic of modern life cannot emerge. If objects like automobiles, satellites, fiber optic cables, the internet, etc., open up as many possible relations at the level of parts as they regulate and constrain at the level of elements, then this is because the effects of technology are never unilateral. Is it an accident that the sexual revolution occurred in the 60's when young people now had a "mobile bedroom" in the form of cars away from the prying eyes of their parents? The internet, personal computers, and smart phones played an important role in the Egyptian Revolution of 2011, allowing for the formation of collective bodies different from those the Egyptian system sought to produce through mechanisms of the police, propaganda, and so on. Television cameras played a significant role in the Civil Rights and Peace Movements of the 60's by allowing the general public to witness events surrounding the oppressive exercise of power and the brutality of warfare. Rogue objects are thus double-edged swords that are often both necessary for the maintenance of certain objects or systems and that open possibilities that introduce entropy into these systems.

Distributions of the sensible code between noise and order through their distinctions and the operations that are governed through their distinctions. In previous social systems, for example, the homosexual is counted not as an element within the social system, but as noise. When the homosexual does appear in such social systems, he appears not as a viable element but as someone suffering from, perhaps, a sickness requiring treatment. That treatment then consists in a series of operations by which this "deviant" person is constituted as an element or through which their action is regulated and guided by 
other elements in the community to occupy a sanctioned position as heterosexual element. The situation here differs little from the manner in which the body generates antibodies to regulate rogue organisms, cells, and viruses that enter the body. Such ways of relating to homosexuality persist today among many conservative Christian communities or macro-level objects. Thus, for example, when it was discovered that Ted Haggard, leader of the National Association of Evangelicals, was engaging in homosexual acts, he did not proclaim himself gay, but rather entered treatment to be cured of his " $\sin$ ". This treatment was a way of constituting him as a sanctioned and legitimate element within that autopoietic object.

Likewise, noise can consist of occurrences that aren't merely unsanctioned forms of relations within a macro-level object, but can also consist of appearances or manifestations not counted or visible to the macro-level object at all. This occurs, for example, in the case of illegal immigrants that are parts of the macro-level object, but which are largely invisible to that macro-level object. In much the same way that I cannot sense the world through sonar, here the larger-scale object cannot "sense" or encounter these objects despite the fact that they are included in the social system (and often included as necessary elements for the social system to function in the way that system functions through their labor).

\section{Queer Politics and Disidentification}

From the foregoing, it is clear that two possibilities of politics are foreclosed: politics that is sometimes disparagingly referred to as "identity politics" and politics premised on the recognition of identities. The reason that politics, as outlined here, cannot consist in the recognition of identities is that identities are the result of and the way in which a system counts elements within a system. Identities are the result of the mechanisms or operations by which elements and their relations are constituted by a system and by which sanctioned appearances or fields of visibility within a particular system are defined. Thus the following is a tautology: to be an identity is to be an element. Yet as we have seen in the foregoing, politics pertains to the appearance or manifestation of parts that are in excess of a system and withdrawn from a macroscale object. Identities belong to a system of governance or the mechanisms by which parts are constituted as elements, whereas politics always pertains to parts that contest the endo-structure of macro-scale objects and that are not counted as elements within that distribution of the sensible. As such, all politics is an-archic insofar as it is the appearance of that which is not counted as well as the manifestation of unsanctioned relations.

Here we must proceed with care, for parts that appear at the site of the political might very well be counted as elements by the system in which they appear. The question then is how it is possible for something to simultaneously be a part that is uncounted within a macro-scale object and be an element within a macro-scale object? To understand how this is possible we must recall that elements are not merely isolated units, but that they are units consisting of regulative relations to other elements in a particular macro-level object. The appearance of a part in the site of the political is thus often the appearance of an entity that contests the manner in which it is counted as an element and the system of sanctioned relations that regulate it. Take the example of Rosa Parks. When, on December $1^{\text {st }}, 1955$, Rosa Parks refuses to give up her 
seat on the bus to a white person, she has transitioned from being an element in this social assemblage to being a part that appears at the site of the political. Parks' act simultaneously discloses the system of relations governing elements that belong to this social system (whites enjoy pride of place over blacks, blacks are to go to the back of the bus, etc.) and this social system's way of counting, organizing body, and the mechanisms by which these relations are produced (the bus driver's orders, the legal system that segregates bodies, the hisses of other white passengers and so on). Yet she also disidentifies herself as an element, by revealing that other relations are possible (egalitarian relations) and by contesting the miscount that constitutes blacks and whites as elements within this system. Rosa Parks refuses to obey this system of constituting elements and relating elements to one another.

In refusing to cede her place, the system of counting is thus contested and the volcanic anarchy of parts and their infinite possible relations beneath macro-scale objects is revealed. Something that is coded as impossible within this macro-scale object appears. This part where the elemental is contested is the moment of subjectification, and every subjectification involves disidentification. As Rancière observes, "[a]ny subjectification is a disidentification, removal from the naturalness of a place, the opening up of a subject space where anyone can be counted since it is the space where those of no ac-count are counted, where connection is made between having a part and having no part." ${ }^{29}$ In refusing to cede her place, Parks challenges the naturalness of her place as a black person: that she belongs at the back of the bus.

Yet why should such moments of subjectification entail that the subject of such acts does not pre-exist their act?
As Rancière remarks, "[...] parties do not exist prior to the declaration of wrong. Before the wrong that its name exposes, the proletariat has no existence as a real part of society. What is more, the wrong it exposes cannot be regulated by way of some accord between the parties." 30 This is precisely because the parts that appear at the site of the political are precisely entities that do not exist from the standpoint of the larger-scale system. The political subject is therefore the invention of a new entity that transforms the larger-scale object or even attempts to destroy it, not the recognition of an entity that already existed. Rancière writes,

[p]olitical subjectification redefines the field of experience that gave to each their identity with their lot. It decomposes and recomposes the relationships between the ways of doing, of being, and of saying that define the perceptible organization of the community, the relationships between the places where one does one thing and those where one does something else, the capacities associated with this particular doing and those required for another... A political subject is not a group that "becomes aware" of itself, finds its voice, imposes its weight on society. It is an operator that connects and disconnects different areas, regions, identities, functions, and capacities existing in the configuration of a given experience... ${ }^{31}$

The political subject is not an entity, but an operator and a set of operations that both constitute a new object -"the party" - and that reconfigure the relations among elements within a larger-scale object. If politics cannot consist in the recognition of identities according to the endo-consistency and operations of a larger-scale operation, then this is precisely because subject as operator of the site of an-anarchy among parts both constitutes a new entity and transforms the relations governing the higher-scale object. 
If the subject of this politics is better called queer than, as Rancière names it, proletariat, then this is because this subject that appears where it should not appear contests the naturalness of the order underlying the larger-scale object and its assignment of roles and ways of doing. The queer is precisely that which appears unnatural, out of place, or as a violation of a particular natural order. The queer is precisely that "unnatural" an-archy of nature that bubbles beneath every "natural" order. As such, the queer is that which reveals the possibility of parts to always relate otherwise than the mechanisms that constitute them as elements would prescribe. In this regard, the politics of the proletariat within a Marxist framework, feminist politics, environmental politics, animal rights politics, disabilities politics, etc., are equally "queer" for all these subjectifications reveal the excess of parts that are uncounted. If queer theory and politics initially stumbled on issues of gender and sexual orientation, then this is because, as Deleuze and Guattari argue, the libidinal is not merely one domain among others with respect to autopoietic systems, but simultaneously marks the volcanic anarchy of parts dwelling within the elements of autopoietic systems and one of the primary sites through which social systems reproduce their organization among elements through assigning roles to genders, constituting genders, forming libidinal attachments to various identities, institutions, parties, religions, and so on..$^{32}$ What is important is that the political subject is that site and its operations that upset these mechanisms of reproduction and that produce a new form of organization. In this regard, the political process does not consist in a transition from dark objects to bright objects, but rather in the transition from dark objects to rogue objects. For it is in the appearance of rogue objects that bright objects are either reconfigured or destroyed.

\section{Who Can Speak?}

All that remains is the question of who can constitute a subject. In Vibrant Matter, Jane Bennett observes that,

When asked in public whether he thought that an animal or a plant or a drug or a (nonlinguistic) sound could disrupt the police order [the distribution of the sensible], Rancière said no: he did not want to extend the concept of the political that far; nonhumans do not qualify as participants in a demos; the disruption effect must be accompanied by the desire to engage in reasoned discourse. ${ }^{33}$

For Rancière a political subject must always be a human object. However, here Rancière seems to both involve himself in a contradiction and undermine the most attractive feature of his political philosophy. On the one hand, Rancière seems to involve himself in a contradiction insofar as the whole point of his opposition between the distribution of the sensible and the political subject is that the site of politics or speech is contested such that it is marked by the appearance of a part that, from the standpoint of the larger-scale object, is incapable of speaking yet that still manages to speak. Yet in claiming that only humans speak, Rancière decides a priori what constitutes a political subject. However, when we talk about minorities, women, the proletariat, "the mad," etc., from the standpoint of the dominant regime of the sensible, we are talking precisely of entities that have been coded as incapable of speech, as inhuman, from the standpoint of the dominant object. The mad are coded as incapable of speech because they lack logos, women and minorities because they lack reason, workers because they cannot simultaneously devote themselves to their labor and engage in public discourse, and for this reason, the 
distribution of the sensible argues, they are in need of being governed just as a child requires parents to govern them. Yet this is precisely what politics contests.

On the other hand, the most attractive feature of Rancière's political thought is that we never know $a$ priori who and what is capable of speaking and participating. Women, people with "alternative sexualities", the mad, cyborgs, computers, whales? We do not know. The parts that compose a larger scale object are always what Timothy Morton has called "strange strangers." 34 From the standpoint of elements, there is always something inscrutable in their withdrawnness that refuses to be reduced to an element. Yet if we never know what part can suddenly appear and speak, there seems to be no reason to restrict the domain of political subjects to the human. Indeed, any part, human or otherwise, can rise up within an assemblage or larger-scale object and force its reconfiguration, the disconnection of certain elements and new connections among elements. These moments where nonhuman agents such as cane toads, natural gas leaks produced through fracking, and hurricanes can rise up and disrupt the orderly auto-reproduction of systems look suspiciously like the agencies of political subjects.

And this, perhaps, is the queerest dimension of the politics advocated by onticology: In a resolutely posthumanist turn, onticology refuses to restrict the political subject to the human. We do not know a priori what entities, what parts, human and nonhuman, might come to occupy the an-archic site of the political. In an age increasingly dominated by ecological crisis and technological transformation, this queer posthumanism is needed more than ever.
Notes:

1. For a detailed treatment of the properties of objects, cf. Levi R. Bryant, The Democracy of Objects (Ann Arbor: Open Humanities Press, 2011), chapters 4-5.

2. Jacques Rancière, Disagreement: Politics and Philosophy (Minneapolis: University of Minnesota Press, 1999), 9.

3. Online Etymology Dictionary, "Queer," http://www.etymonline. com/index.php?term=queer.

4. For a discussion of this crisis and its implications, cf. Michael O'Rourke, "The Afterlives of Queer Theory," in Continent, Volume 1, No. 2 (2011): 102-116.

5. I develop the evental nature of politics and ethics in "The Ethics of the Event: Deleuze and Ethics without A $\rho \chi$,", in Deleuze and Ethics, eds. Nathan Jun and Daniel W. Smith (Edinburgh: Edinburgh University Press, 2011), 21-43.

6. Humberto R. Maturana and Francisco J. Varela, "Autopoiesis: The Organization of the Living", in Autopoiesis and Cognition: The Realization of the Living (Boston: D. Reidel Publishing Company, 1980), 77-84.

7. Ibid., 78-79

8. Niklas Luhmann, Social Systems, trans. Dirk Baecker (Stanford: Stanford University Press, 1995), 22.

9. Ibid., 21-22

10. Ibid., 21

11. Ibid., 17.

12. Alain Badiou, Being and Event, trans. Oliver Feltham (London: Continuum, 2005), chapter 7.1.

13. Peter Hallward, Badiou: A Subject to Truth (Minneapolis: University of Minnesota Press, 2003), 85.

14. Jacques Rancière, Disagreement: Politics and Philosophy, trans. Julie Rose (Minneapolis: University of Minnesota Press, 1999), 6.

15. Niklas Luhmann, Social Systems, 16-17.

16. Ibid., 25.

17. Ibid., 13.

18. Ibid., 17

19. Niklas Luhmann, The Reality of the Mass Media, trans. Kathleen Cross (Stanford: Stanford University Press, 2000), 5.

20. Niklas Luhmann, "The Cognitive Program of Constructivism and the Reality That Remains Unknown," in Theories of Distinction: 
Redescribing the Descriptions of Modernity, ed. William Rasch (Stanford: Stanford University Press, 2002), 135.

21. Nicklas Luhmann, "Identity-What or How?" in Theories of Distinction, 115.

22. Luhmann, The Reality of the Mass Media, 11.

23. Cf. Graham Harman, Tool-Being: Heidegger and the Metaphysics of Objects (Chicago: Open Court, 2002). "Onticology" is the name for my particular ontology as developed in The Democracy of Objects, whereas "object-oriented philosophy" is the name for Harman's metaphysics. "Object-oriented ontology," by contrast, refers to any ontology that affirms the independent existence of objects.

24. Gilles Deleuze, Difference and Repetition, trans. Paul Patton (New York: Columbia University Press, 1994), 68.

25. Cf. Immanuel Kant, Critique of Pure Reason, Paul Guyer and Allen w. Wood, trans., (Cambridge: Cambridge University Press, 1998), Transcendental Doctrine of Elements, Parts 1-2.

26. Benedict de Spinoza, Ethics, in Spinoza: Complete Works, Michael L. Morgan, trans., (Indianapolis: Hackett Publishing Company, Inc., 2002), 278

27. Jacques Rancière, "The Distribution of the Sensible: Politics and Aesthetics," in The Politics of Aesthetics, trans. Gabriel Rockhill (London: Continuum, 2004), 12.

28. For an account of the ontological status of operations within an object-oriented ontology framework cf. Ian Bogost, Unit Operations: An Approach to Videogame Criticism (Cambridge, MA: The MIT Press, 2006), chapter 1. Ian Bogost and I are largely in accord with respect to how objects constitute themselves as unities through operations.

29. Rancière, Disagreement, 36.

30. Ibid., 39.

31. Ibid., 40.

32. Cf. Gilles Deleuze and Félix Guattari, Anti-Oedipus: Capitalism and Schizophrenia, trans. Robert Hurley, Mark Seem, and Helen R. Lane (Minneapolis: University of Minnesota Press, 1983).

33. Jane Bennett, Vibrant Matter: A Political Ecology of Things (Durham: Duke University Press, 2010), 106.

34. Timothy Morton, The Ecological Thought (Cambridge, MA: Harvard University Press, 2010). 